\title{
WUJUD KEBUDAYAAN DALAM TRADISI SUNA RO NDOSO: KAJIAN ETNOLINGUISTIK
}

\author{
Aryanah Hilman ${ }^{1}$, Burhanuddin ${ }^{2}$, Saharudin $^{3}$ \\ FKIP Universitas Mataram \\ Magister Pendidikan Bahasa Indonesia FKIP Unram ${ }^{1,2,3}$ \\ Alamat surel: aryanah.hilman23@gmail.com
}

\begin{abstract}
Abstrak
Penelitian ini bertujuan untuk mendeskripsikan wujud kebudayaan yang terdapat dalam tradisi suna ro ndoso menggunakan pendekatan etnolinguistik. Jenis penelitian yang digunakan adalah kualitatif deskriptif, metode penelitian menggunakan metode observasi partisipatif dan metode cakap/wawancara. Tahapan analisis data yang dilakukan dalam penelitian ini yaitu metode padan intralingual. Hasil analisis data dalam penelitian ini disajikan melalui metode informal, metode formal, dan metode deskriptif. Hasil penelitian menunjukkan bahwa wujud dari ide, gagasan, nilai, norma, dan peraturan terlihat sebagai wujud ide/gagasan tentang ketuhanan, keselamatan, dan keberanian. Wujud aktivitas serta tindakan berpola ditemukan kurang lebih sekitar 13 kumpulan aktivitas serta tindakan berpola dari manusia dalam masyarakat pada prosesi suna ro ndoso. Wujud sebagai benda-benda hasil karya manusia yang terdapat dalam prosesi suna ro ndoso masyarakat Dompu, ditemukan kurang lebih sekitar 50.
\end{abstract}

Kata Kunci: Wujud Kebudayaan, Suna Ro Ndose, dan Etnolinguistik

\section{A. PENDAHULUAN}

Daerah-daerah yang berada di Indonesia memiliki banyak kearifan lokal, budaya, tradisi, adatistiadat, bahasa, serta ritual adat atau upacara adat berbeda-beda, menjadi pembeda antara daerah satu dengan daerah lainnya. Kearifan-kearifan lokal dan budaya yang dimiliki tersebut memiliki filosofi dan kandungan makna yang hampir sama, merupakan kekayaan bangsa yang dilindungi dan dilestarikan keberadaannya oleh negara.

Sebagai salah satu daerah yang memiliki kebudayaan dan kearifan lokal yang terjaga, Daerah Dompu sebagai salah satu daerah yang berada di Provinsi Nusa Tenggara Barat (NTB) memiliki berbagai macam upacara adat yang dilakukan. Masyarakat Dompu memiliki kepercayaan bahwa dengan melaksanakan prosesi upacara adat, berarti telah menghargai segala warisan yang ditinggalkan oleh nenek moyang. Upacara adat yang masih sering dilaksanakan adalah upacar adat sunatan. Upacara sunatan di dalamnya terdapat banyak simbol yang secara tidak langsung dapat mencerminkan pola pikir masyarakat.

Sunatan oleh masyarakat Dompu disebut suna ro ndoso, merupakan bagian dari upacara adat yang senantiasa dilakukan oleh orang-orang yang memiliki budaya, bukan hanya sebagai ritual semata, melainkan juga karena tradisi yang sudah mendarah daging bagi para pelaku yang senantiasa memelihara adat tersebut. Suna ro ndoso sebagai salah satu tradisi adat, dalam pelaksanaannya banyak memiliki makna dari simbol-simbol yang digunakan, baik simbol verbal maupun simbol nonverbal. 
Kenyataannya banyak dari masyarakat Dompu yang kurang mengetahui filosofi pelaksanaan dan makna-makna yang tergantung dalam pelaksanaan prosesi suna ro ndoso. Menjadi hal yang disayangkan apabila masyarakat Dompu sendiri tidak mengetahui wujud kebudayaan yang dimiliki. Suna ro ndoso terdapat wujud kebudayaan disebutkan oleh Koentjaraningrat (2009: 150) bahwa ada tiga bentuk wujud kebudayaan yaitu a. ide, gagasan, nilai, norma, peraturan, b. aktivitas serta tindakan berpola dari manusia dalam masyarakat, dan c. benda-benda hasil karya manusia. Sebagai contoh dalam prosesi suna ro ndoso terdapat simbol seperti sampari dalam upacara compo sampari. Sampari (keris) merupakan senjata tajam terbuat dari besi pilihan yang menjadi alat pelindung diri bagi masyarakat Dompu. Sampari memiliki makna dalam prosesi suna ro ndoso sebagai lambang berwujud benda yang mengajarkan keberanian dan kekuatan kepada anak yang akan disuna ro ndoso. Selain sampari ada pula kapanca, fare, bongi, ilo lili, dan seterusnya. Wujud kebudayaan yang berupa aktivitas adalah peta kapanca. Peta kapanca merupakan upacara dalam pelaksanaan suna ro ndoso yaitu penempelan kapanca (inai) kepada anak yang akan disuna ro ndoso oleh ibu-ibu berjumlah sekitar lima atau tujuh orang. Maksud pelaksanaan peta kapanca adalah anak-anak diajarkan untuk memiliki sifat rela berkorban dan bertanggung jawab terhadap suatu pekerjaan yang diberikan walau darah bercucuran. Hal ini ditandai dengan warna merah yang terdapat pada daun inai tersebut. Contoh aktivitas lainnya seperti compo sampari, maka, ncala, boe genda, dan sebagainya.

Pelaksanaan suna ro ndoso banyak terdapat soji ro sangga (bahan dan alat). Soji ro sangga tersebut memberikan kesan adanya berbagai jenis produksi sebagai potensi alam lingkungan yang merupakan sumber penghidupan masyarakat. Upacara adat sebagai warisan budaya leluhur memegang peranan penting dalam kehidupan bermasyarakat. Selain itu, upacara adat mengandung nilai-nilai serta norma-norma yang masih dipatuhi oleh masyarakat pendukungnya.

Seiring dengan terjadinya perubahan zaman, cepatnya laju modernisasi, dan globalisasi, pelaksanaan serta keberadaan dari tradisi atau ritual adat sebagai salah satu kearifan lokal tersebut mulai memudar kemudian perlahan ditinggalkan oleh generasi-generasi penerusnya. Budaya, adaistiadat, bahasa, dan tradisi yang di dalamnya merupakan salah satu kearifan lokal suatu daerah yang perlahan mulai ditinggalkan tersebut, perlu adanya suatu tindakan yaitu dengan dilakukannya kajian mendalam yang mengaitkan bahasa, budaya, dan ritual atau prosesi adat dengan tujuan pemertahanan dan pelestarian segala kekayaan bahasa dan budaya tersebut.

Sebagai kelompok yang memiliki rasa tanggung jawab untuk tetap mempertahankan dan melestarikan tradisi adat. Penelitian tentang prosesi, wujud kebudayaan, dan nilai-nilai yang terdapat dalam prosesi suna ro ndoso penting untuk dilakukan. Generasi penerus harus mengetahui dan memahami segala bentuk kearifan lokal, budaya, adat-istiadat, dan bahasa yang menjadi ciri khas dari kebudayaan daerah yang dimiliki tersebut dengan kebudayaan yang dimiliki oleh daerah lain. 
Penelitian tentang upacara adat ataupun prosesi adat sudah banyak dilakukan. Aspek kajiannya pun beragam, mencakup aspek nilai-nilai yang terkandung dalam prosesi adat, kepercayaan, atau takhayul tradisional yang masih diyakini kebenarannya, sampai mantra-mantra tradisional yang terus dipertahankan oleh masyarakatnya. Namun, dari semua penelitian yang sudah dilakukan, belum ada yang meneliti dan membahas secara detail tentang wujud kebudayaan yang terdapat dalam prosesi suna ro ndoso tradisi masyarakat Dompu.

\section{B. KAJIAN TEORI}

Pateda (1991) menjelaskan etnolinguistik merupakan perpaduan antara etnologi dan linguistik. Etnolinguistik adalah ilmu yang mengkaji seluk beluk keterkaitan aneka penggunaan bahasa dengan pola kebudayaan (Sudaryanto, 1996 dalam Suarsini, 2017: 31). Ahimsa-Putra (1997) mengatakan bahwa etnolinguistik merupakan salah satu bidang ilmu yang sangat menarik karena di lahan inilah dapat ditemukan suatu hal yang sangat penting, yakni proses terbentuknya kebudayaan dan hubungannya dengan bahasa, serta kebudayaan yang terbentuk tersebut terus-menerus mengalami perubahan, baik disadari maupun tidak disadari oleh pendukung kebudayaan tersebut, seperti tercermin dalam bahasa mereka (dalam Baehaqi, 2014: 181). Lebih lanjut Matthews (1997) menjelaskan bahwa pemahaman budaya dapat diketahui dari hubungan yang berbeda atau variasi antara struktur bahasa dengan kebudayaan suatu masyarakat yang dikaji di dalam model pengkajian yang dilakukan tersebut (dalam Abdullah 2013: 59).

Sementara itu, Koentjaraningrat (2006: 150-151) mengatakan bahwa kebudayaan itu ada tiga wujudnya, yaitu, 1) Wujud kebudayaan sebagai suatu kompleks dari ide, gagasan, nilai, norma, peraturan, dan sebagainya. Wujud pertama ini merupakan wujud ideal dari kebudayaan. Sifatnya abstrak, tidak dapat diraba atau difoto. Ide dan gagasan manusia banyak yang hidup bersama dalam suatu masyarakat, memberi jiwa kepada masyarakat itu. Gagasan itu satu dengan yang lain selalu berkaitan menjadi suatu sistem, 2) Wujud kebudayaan sebagai suatu kompleks aktivitas serta tindakan berpola dari manusia dalam masyarakat. Wujud kedua dari kebudayaan disebut sistem sosial atau social system. Sistem sosial ini terdiri dari aktivitas-aktivitas manusia yang berinteraksi, berhubungan, dan bergaul satu sama lain. Sistem sosial itu bersifat konkret, terjadi di sekeliling kita sehari-hari, dapat diobservasi, difoto, dan didokumentasikan, dan 3) Wujud kebudayaan sebagai benda-benda hasil karya manusia. Wujud kebudayaan ini disebut kebudayaan fisik. Berupa seluruh hasil fisik dan aktivitas, perbuatan, dan karya semua manusia dalam masyarakat. Sifatnya paling konkret dan berupa benda-benda atau hal-hal yang dapat diraba, dilihat, dan difoto.

\section{METODE PENELITIAN}


Jenis penelitian yang digunakan merupakan jenis penelitian deskriptif kualitatif. Metode kualitatif dalam hal ini digunakan sebagai prosedur penelitian yang menghasilkan data deskriptif berupa kata-kata tertulis atau lisan dari orang-orang dan perilaku yang diamati. Penelitian ini akan dilakukan di daerah kecamatan Dompu, Kabupaten Dompu, Provinsi Nusa Tenggara Barat. Lokasi penelitian ini dipilih karena pada beberapa peristiwa, masyarakatnya selalu melaksanakan upacara adat, terutama melaksanakan prosesi suna ro ndoso.

Data penelitian ini adalah berupa keterangan-keterangan yang diberikan oleh informan penelitian, yaitu tentang prosesi dan wujud kebudayaan yang terkandung pada rangkaian prosesi adat suna ro ndoso tradisi masyarakat Dompu. Data tersebut kemudian akan dianalisis berdasarkan wujud kebudayaan pada prosesi adat suna ro ndoso tradisi masyarakat Dompu yang tercermin dari istilahistilah yang digunakan. Adapun metode pengumpulan data dalam penelitian ini adalah metode observasi partisipatif dan metode cakap. Hasil analisis data dalam penelitian ini disajikan melalui metode informal, metode formal, dan metode deskriptif. Hasil analisis data juga akan ditampilkan secara deskriptif melalui kalimat-kalimat yang biasa digunakan dalam penelitian ilmiah serta menggunakan lambang-lambang bahasa.

\section{HASIL DAN PEMBAHASAN}

Prosesi suna ro ndoso merupakan salah satu prosesi adat yang dilakukan oleh masyarakat Dompu. Suna ro ndoso biasa dilakukan pada pagi hari atau sore hari setelah semua proses dan tahapan dari prosesi suna ro ndoso dikerjakan seperti peta kapanca, compo sampari, maka, dan ncala. Sebelum memaparkan prosesi suna ro ndoso, akan dipaparkan istilah-istilah kebahasaan dan aktivitas-aktivitas yang ditemukan baik berupa perilaku verbal maupun nonverbal. Istilah-istilah kebahasaan dalam aktivitas-aktivitas yang ada dalam prosesi suna ro ndoso antara lain diklasifikasikan sebagai berikut.

\section{Wujud istilah prosesi suna ro ndoso ditinjau dari aspek kabahasaan}

\subsection{Berdasarkan kategori kata}

kategori kata dalam bahasa Indonesia terdiri dari nomina, pronomina, verba, adjektiva, numeralia, adverbia, introgativa, proposisi, dan sebagainya.

\section{a. Wujud berbentuk nomina}

Wujud istilah-istilah berbentuk nomina dalam prosesi suna ro ndoso antara lain.
1. Sampari
6. Tambaku
11. Bongi monca
2. Roo kapanca
7. Nahi
12. Bongi kala
3. Roo nahi
8. Rongko roo taa
13. Bongi mee
4. U'a
9. Karodo
14. Bongi bura
5. Afu
10. Bongi
15. Fare kapi 

16. Fare monca
20. $\mathrm{Oi}$
24. Niu sambori
17. Fare kala
21. Roa dana
25. Ua sambori
18. Fare mee
22. Malanta monca
26. Nahi sapete
19. Fare bura
23. Malanta bura
27. Dobu
28. Karencu
36. Janga sanggapi
44. Kalo
29. Kahuntu
37. Janga mori
45. Lili
30. Pangaha bunga
38. Jago karaba
46. Jima rima
31. Pangaha arunggina
39. dupa
47. Jima ancu
32. kapore
40. Genda
48. Kawari
33. Roo sancara
41. No
49. Baju bodo
34. Buja
42. Sarone
35. Dolu janga
43. Раји

\section{b. Wujud berbentuk verba}

Wujud istillah-istilah berbentuk verba dalam prosesi suna ro ndoso antara lain.
1. Compo sampari
5. Ziki
9. Saraso
2. Peta kapanca
6. Heko sampari
10. Ngaji
3. Ncala
7. Kadoho
11. Boe genda
4. Maka
8. Suna ro ndoso
12. Bolo

\subsection{Berdasarkan jumlah kata pembentuknya}

Wujud istilah-istilah maupun aktivitas-aktivitas berdasarkan jumlah kata pembentuk adalah sebagai berikut.

\section{a. Satu kata}

1. Sampari [sampari] 'keris'

2. Roo [ro?o] 'daun'

3. Kapanca[kapanca] 'pancar/pewarna kuku dari daun inai'

4. Nahi [nahI] 'sirih'

5. Ua $[\mathrm{u}$ ?a] 'pinang'

6. Afu [afu] 'kapur sirih'

7. Tambaku[tambaku] 'tembakau'

8. Karodo [karodO] 'makanan dari tepung dicampur kelapa dan gula'

9. Bongi [bonI] 'beras'

10. Oi [OI] 'air'

11. Malanta[malanta] 'kain kafan'
12. Dobu [dO? $\underline{b u}]$ 'tanaman tebu'

13. Karencu [karEncu] 'ketupat yang dibuat memanjang'

14. Kahuntu [kahuntu] 'ketupat yang dibuat persegi'

15. Kapore [kapOrE] 'makanan dari tebung yang diberi bumbu kelapa dan gula merah'

16. Dolu [dOlu] 'telur'

17. Sancara [sancara] 'daun sancara'

18. Buja [buja] 'tombak'

19. Dupa[dupa] 'dupa, kemenyan, asapnya berbau harum' 
20. Genda [gEnda] 'gendang'

21. No [nO] 'gong'

22. Sarone [sarone] 'seruling'

23. Paju [paju] 'payung'
24. Kalo [kalO] 'pisang'

25. Lili [1III] 'lilin'

26. Kawari [kawarI] 'kalung'

\section{b. Dua kata atau lebih}

1. Roo kapanca [rO?O (daun) + kapanca (pancar/inai)] 'daun pancar/inai untuk memerahkan kuku'

2. Roo nahi [rO?O (daun) + nahI (sirih)] 'daun tanaman sirih'

3. Bongi monca [bopI (beras) + mOnca (kuning)] 'beras berwarna kuning'

4. Bongi kala [bonI (beras) + kala (merah)] 'beras berwarna merah'

5. Bongi mee $[\underline{b} O \eta y I ~(b e r a s)+m E ? E(h i t a m)]$ 'beras berwarna hitam'

6. Bongi bura $[\underline{b} O n I ~(b e r a s)+\underline{b} U r a($ putih)] 'beras berwarna putih'

7. Fare kala [farE (padi) + kala (merah)] 'padi berwarna merah'

8. Fare mee [farE (padi) $+\mathrm{mE}$ ?E (hitam)] 'padi berwarna hitam'

9. Fare bura [farE (padi) + bura (putih)] 'padi berwarna putih'

10. Fare monca [farE (padi) + mOnca (kuning)] 'padi berwarna kuning'

11. Fare kapi [farE (padi) + kapI (jepit)] 'padi ladang yang diikat/dijepit'

12. Jago karaba [jagO (jagung) + karaba (ayak/sangrai) 'jagung yang dimasak dengan cara diayak atau disangrai'

13. Pangaha bunga [panaha (jajan) + buya (bunga)] 'jajan terbuat dari tepung dan beras ketan yang berbentuk bunga'

14. Pangaha arunggina [panaha (jajan) + aruygIna (rengginang)] 'panganan yang terbuat dari beras ketan, berbentuk bulat; rengginang'

15. Roa dana [rOa (tempayan) + dana (tanah)] 'tempayan yang terbuat dari tanah liat'

16. Rongko roo taa [rojkO rO?O ta?a] 'rokok yang terbuat dari daun lontar'

17. Malanta monca [malanta (kafan) + mOnca (kuning)] 'kain kafan berwarna kuning'

18. Malanta bura [malanta (kafan) + bUra (putih)] 'kain kafan berwarna putih'

19. Niu sambori [nI?U (kelapa) + samborI (setandan)] 'setandan buah kelapa'

20. Ua sambori [u?a (pinang) samborI (setandan)] 'setandan buah pinang'

21. Nahi sapete [nahI (sirih) + sapete (seikat)] 'seikat daun sirih'

22. Roo sancara [rO?O (duan) + sancara] 'daun sancara'

23. Janga sanggapi [jaya (ayam) + saygapi (panggang)] 'ayam yang dimasak dengan memanggang'

24. Janga mori [jana (ayam) + mOrI (hidup)] 'ayam yang masih hidup'

25. Jima rima [jIma (gelang) + rIma Tangan)] 'gelang untuk tangan' 
26. Jima ancu [jIma (gelang) + ancu (bahu)] 'gelang untuk bahu'

27. Baju bodo [ $\underline{b} a j u(b a j u)+$ bOdO ] 'baju khas atau pakaian adat Suku Bugis Makassar, tapi digunkan juga oleh masyarakat Dompu'

\section{Wujud Kebudayaan dalam Prosesi suna ro ndoso Masyarakat Dompu}

Adapun wujud kebudayaan dalam prosesi suna ro ndoso masyarakat Dompu adalah sebagai berikut.

\section{Wujud kebudayaan sebagai suatu ide, gagasan, nilai, norma, dan peraturan}

wujud kebudayaan berupa suatu ide, gagasan, nilai, norma, dan peraturan merupakan wujud kebudayaan yang abstrak. Wujud ini sulit diidentifikasi karena tempatnya berada dalam alam pikiran masyarakat tempat kebudayaan hidup. Wujud berupa ide dan gagasan saling berhubungan membentuk sistem yang disebut adat-istiadat. Wujud ide dan gagasan yang tercermin dari prosesi suna ro ndoso masyarakat Dompu adalah sebagai berikut.

\section{a. Wujud ide/gagasan tentang ketuhanan}

Wujud ide/gagasan dalam prosesi suna ro ndoso merupakan wujud kebudayaan hasil karya manusia hubungannya dengan masalah keagamaan atau religi masyarakat Dompu. Masyarakat Dompu meyakini bahwa serangkaian upacara atau prosesi suna ro ndoso yang dilakukan tujuannya hanya mengharapkan ridho Tuhan Yang Maha Esa, Allah SWT. Hal tersebut terlihat dalam setiap tahapan-tahapan yang dilakukan seperti membaca doa-doa seraya memeohon pertolongan dan perlndungan kepada Allah SWT. agar selama prosesi suna ro ndoso diberi kelancaran dari mulainya acara sampai acara yang diadakan selesai.

\section{b. Wujud ide/gagasan tentang keselamatan}

Wujud tentang keselamatan merupakan wujud ide/gagasan karena prsosesi suna ro ndoso menandakan bahwa anak yang disunat sudah akan menuju kedewasaan dalam hidupnya. Suna ro ndoso berusaha memberikan gambaran dan mempersiapkan anak yang akan di sunat kelak setelah dewasa diberi keselamatan. Semua hal-hal buruk yang ada dibuang dan dibersihkan. Wujud ide/gagasan tentang keselamatan juga bertujuan pada kseluruhan tahapan upacara diberi kelancaran dan kemudahan dari dimulainya acara sampai selesai.

\section{c. Wujud ide/gagasan tentang keberanian}

Berbagai tahapan prosesi suna ro ndoso bertujuan sebagai pembentuk karakter dan kepribadian anak yang kuat. Semua prosesi suna ro ndoso yang dilakukan merupakan harapan agar anak yang disuna ro ndoso memiliki jiwa kesatria dan keberanian dalam menjalani kehidupannya. Hal tersebut terlihat ketika proses peta kapanca dan compo sampari. Peta kapanca memberikan gambaran ke pada si anak, bahwa kelas saat dewasa harus berani membela kebenaran, melindungi yang lemah walau darah bercucuran di tangan dilambangkan dengan warna merah inai. Demikian 
halnya pada pelaksanaan compo sampari, digambarkan bahwa anak harus memiliki jiwa kesatria, berjiwa pemimpin, dan memiliki rasa tanggung jawab yang dilambangkan dengan kekuatan besi yang dijadikan sampari.

\section{Wujud Kebudayaan Sebagai Suatu Aktivitas dan Tindakan Berpola dari Manusia dalam Masyarakat}

Wujud aktivitas atau sistem sosial dalam masyarakat merupakan tingkah laku dari masyarakat yang dilakukan secara terus menerus dan berulang-ulang. Sistem sosial meliputi segala tindakan dan hubungan bersosialisasi antara satu dengan lainnya. Wujud aktivitas merupakan wujud yang lengkap dan lebih mudah diamati. Prosesi suna ro ndoso ditemukan pada tingkah laku berpola yang dikerjakan oleh masyarakat Dompu selama prosesi dan tahapantahapan dari suna ro ndoso berlangsung. Aktivitas dan tindakan yang dilakukan dalam prosesi suna ro ndoso dapat dilihat sebagai berikut.

\begin{tabular}{|c|c|c|}
\hline No. & Leksikon & Glos \\
\hline 1. & $\begin{array}{l}\text { Peta kapanca } \\
\text { [pEta kapanca] }\end{array}$ & $\begin{array}{l}\text { 'penempelan inai di atas telapak tangan anak-anak yang } \\
\text { akan disuna ro ndoso' }\end{array}$ \\
\hline 2. & $\begin{array}{l}\text { Ziki kapanca } \\
\text { [zIkI kapanca] }\end{array}$ & $\begin{array}{l}\text { 'syair zikir berisi pujian ke hadapan Allah dan Rasul, ziki } \\
\text { kapanca dilagukan oleh beberapa orang pezikir' }\end{array}$ \\
\hline 3. & Kadoho [kadOhO] & $\begin{array}{l}\text { 'mendudukkan anak yang akan disuna ro ndoso di hadapan } \\
\text { tamu undangan yang datang' }\end{array}$ \\
\hline 4. & $\begin{array}{l}\text { Compo sampari [cOmpO } \\
\text { samparI] }\end{array}$ & $\begin{array}{l}\text { 'memasangkan keris ke pinggang bagian kiri anak yang } \\
\text { akan disuna ro ndoso, tangan kanan memegang hulu keris } \\
\text { dan tangan kiri memegang sarung keris' }\end{array}$ \\
\hline 5. & $\begin{array}{l}\text { Heko sampari } \\
\text { [hEkO samparI] }\end{array}$ & $\begin{array}{l}\text { 'memutar atau mengantarkan keris keliling tubuh si anak } \\
\text { yang akan disuna ro ndoso diiringi pembacaan selawat' }\end{array}$ \\
\hline 6. & Maka [maka] & $\begin{array}{l}\text { 'bertukas (menari keris), meyentakkan kaki ke depan dan ke } \\
\text { belakang (kaki kanan) tiga kali' }\end{array}$ \\
\hline 7. & $\begin{array}{l}\text { Baca doa labo japa tanga } \\
\text { [baca dO?a labo japa tana] }\end{array}$ & $\begin{array}{l}\text { 'membaca doa penutupan acara peta kapanca dan compo } \\
\text { sampari, serta bersalaman dan berjabatangan dengan anak- } \\
\text { anak, orang tua, dan keluarga yang mengadakan suna ro } \\
\text { ndoso' }\end{array}$ \\
\hline
\end{tabular}




\begin{tabular}{|c|c|c|}
\hline 8. & Ngaji [yajI] & 'pembacaan ayat-ayat suci alquran' \\
\hline 9. & $\begin{array}{l}\text { Boe genda } \\
{[\underline{b} O E \text { gEnda }]}\end{array}$ & $\begin{array}{l}\text { 'memainkan alat musik tradisional Dompu yang terdiri dari } \\
\text { genda, ro no, dan sarone' }\end{array}$ \\
\hline 10. & Ncala [ncala] & $\begin{array}{l}\text { 'terjadinya kerasukan atau mai bolo, masuknya jin } \\
\text { (kesurupan) dalam tubuh sesorang' }\end{array}$ \\
\hline 11. & Bolo [bOlO] & $\begin{array}{l}\text { 'menari karena karasukan Jin dan makhluk halus lainnya } \\
\text { (kesurupan)' }\end{array}$ \\
\hline 12. & $\begin{array}{l}\text { Suna ro Ndoso } \\
\text { [suna } \mathrm{rO} \text { ndOsO] }\end{array}$ & $\begin{array}{l}\text { 'khitanan, upacara sunatan yang dilakukan apabila seorang } \\
\text { anak sudah berusia lima atau enam tahun dan ada juga yang } \\
\text { lebih dari itu' }\end{array}$ \\
\hline 13. & Saraso [sarasO] & 'upacara khitanan anak perempuan masyarakat Dompu' \\
\hline
\end{tabular}

Berdasarkan tabel di atas ditemukan kurang lebih sekitar 13 kumpulan aktivitas serta tindakan berpola dari manusia dalam masyarakat pada prosesi suna ro ndoso, wujud tersebut merupakan aktivitas serta tindakan berpola yang dilakukan dalam tahapan atau aktivitas prosesi suna ro ndoso. Adapun tujuan dari aktivitas di atas dilakukan karena merupakan hal yang tidak dapat terpisahkan. Penjelasan dari masing-masing wujud aktivitas serta tindakan berpola pada prosesi suna ro ndoso.
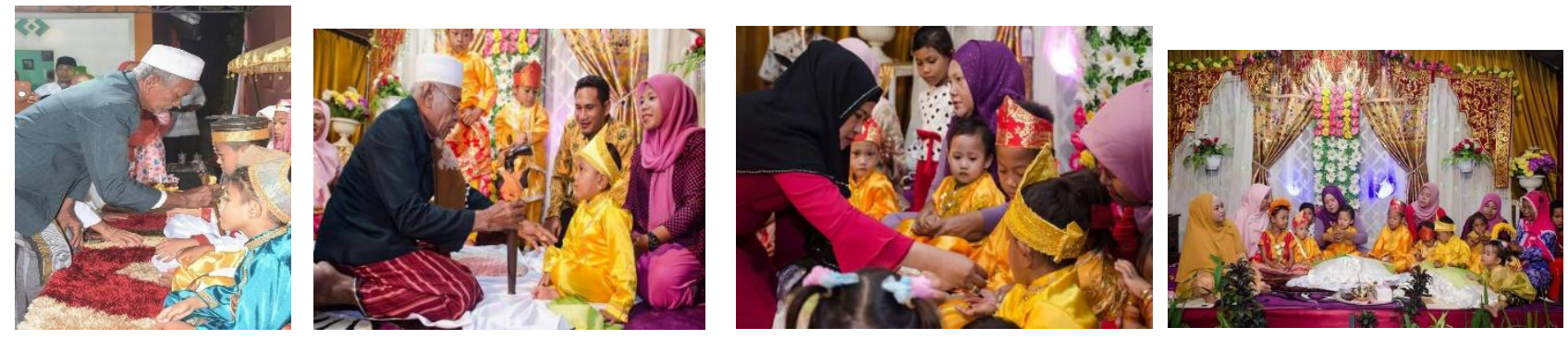

Gambar: aktivitas dalam prosesi suna ro ndoso. Sumber: dokumentasi pribadi.

Peta kapanca merupakan Penempelan kapanca atau inai yang sudah ditumbuk halus, diletakkan di atas telapak tangan anak yang akan disuna ro ndoso, menjadi pelaksana adalah tokoh adat atau orang yang sudah ditunjuk oleh pihak keluarga, biasanya dilakukan oleh ibu-ibu. Pata pelaksanaan peta kapanca diiringi lantunan zikir (ziki peta kapanca) berisi selawat kepada Allah dan Rasul, oleh kelompok pengajian yang diundang oleh pihak orang tua dan keluarga yang mengadakan suna ro ndoso. Anak-anak didudukkan (kadoho) di depan tamu undangan yang hadir. 
Pelaksanan selanjutnya setelah acara peta kapanca akan dilangsungkan acara compo sampari yakni memakaikan keris kepada anak laki-laki yang akan disuna ro ndoso. Pelaksanaan compo sampari adalah dengan memulai memainkan alat musik genda, no, dan sarone. Sampari dihantarkan mengelilingi tubuh anak (heko sampari), diputar di bagian atas kepala, diputar berlawanan arah jarum jam sebanyak tujuh kali, dibacakan selawat dan doa-doa. Compo sampari dilakukan oleh tokoh adat atau orang tua-tua yang syarak hukum yang telah ditunjuk oleh orang tua anak yang akan disuna ro ndoso.

Maka pada umumnya diartikan sebagai bertukas (menari keris) yang dilakukan setelah anak disuna ro ndoso. Pelaksanaannya adalah dimulai dengan seseseorang yang berbadan tegap berlari kecil (seperti orang menari) memegang sampari dengan muka yang garang, membentak-bentak sambil mengeluarkan kata-kata atau kalimat yang memberikan semangat dan keberanian, "tass rumae, huri waura horo, tinggal weipra dingupa". Dipandu dan dipimpin langsung oleh tokoh adat yang sudah ditunjuk untuk melakukan compo sampari, kata-kata atau kalimat yang diucapkan juga sama seperti yang sudah disebutkan di atas, tujuannya adalah untuk memberikan semangat secara langsung ke pada anak yang akan disunat esok hari.

Pada pelaksanaan compo sampari dan maka dilaksanakan alat musik seperti genda dan sarone dimainkan. Begitu genda, no, dan sarone dimainkan (boe genda), beberapa orang atau keluarga yang mengadakan prosesi suna ro ndoso akan melakukan ncala. Ncala merupakan proses terjadinya kerasukan, dalam bahasa Bima biasa disebut mai bolo, yaitu masuknya Jin dan makhluk-makhluk halus lainnya dalam tubuh seseorang. Ncala merupakan bagian yang mengikat dan tidak terpisahkan dari prosesi suna ro ndoso. Hakikatnya kerasukan tersebut terjadi pada saat genda, no, dan sarone dimainkan.

Selesai acara yang sudah disebutkan di atas, dilakukan pembacaan doa dan saling bersalaman (baca doa labo japa tanga). Pembacaan doa tidak lain tujuannya adalah pengharapan kepada Tuhan agar diberi kemudahan dan kelancara selama prosesi suna ro ndoso dilaksanakan. Kemudia dilanjutkan dengan acara bersalaman antara tamu undangan yang hadir dengan anak-anak yang akan disuna ro ndoso beserta orang tua dan keluarga. Memberi ucapan selamat dan dukungan agar acara yang diadakan sesuai dengan rencana pemilik hajatan atau acara.

Pembacaan ayat suci alquran (ngaji) akan dilaksanakan setelah acara peta kapanca dan compo sampari. Sebelum ngaji, orang-orang dipersilahkan masuk ke dalam rumah yang mengadakan acara suna ro ndoso untuk menyantap hidangan yang sudah disiapkan. Ngaji akan dilaksanakan setelah semua hidangan habis disantap. Pembacaan alquran dapat dilakukan dengan membaca beberapa juz tergantung kesanggupan orang yang membaca. Ngaji biasanya dapat dilakukan sampai tengah malam. 
Tahapan akhir atau puncak prosesi suna ro ndoso adalah dilaksanakannya suna ro ndoso dan saraso (bagi anak perempuan). Dilaksanakan pada pagi hari atau sore hari, anak-anak yang akan disuna ro ndoso dipakaikan pakaian seperti pada pelaksanaan peta kapanca dan compo sampari. Dinaikkan di atas tempat yang sudah dipersiapkan (mirip ranjang tempat tidur) bisa juga meja, tidur terlentang. Kemudian orang yang akan menyunat melakukan tugasnya. Dulu, yang melakukan penyunatan (yang menyunat) disebut sando yakni orang yang pandai dan tau tentang tata cara melakukan penyunatan, dilaksanakan dengan cara sangat tradisional yakni dengan menggunakan pisau potong yang tajam atau biasanya juga dapat berupa bilah bambu yang sangat tajam dari bambu pilihan.

3. Wujud kebudayaan sebagai benda-benda hasil karya manusia

\begin{tabular}{|c|c|c|}
\hline No. & Leksikon & Glos \\
\hline 1. & $\begin{array}{l}\text { Roo kapanca }[\mathrm{rO} ? \mathrm{O} \\
\text { kapanca] }\end{array}$ & 'daun pancar/inai untuk memerahkan kuku' \\
\hline 2. & Sampari [samparI] & $\begin{array}{l}\text { 'keris; senjata tajam bersarung, berujung tajam, ada yang } \\
\text { berlekuk-lekuk' }\end{array}$ \\
\hline 3. & Roo nahi [rO?O nahI] & $\begin{array}{l}\text { 'daun sirih; dapat dikunyah bersama dengan pinang, kapur, dan } \\
\text { tembakau' }\end{array}$ \\
\hline 4. & $\mathrm{Ua}[\mathrm{u} ? \mathrm{a}]$ & 'pohon pinang' \\
\hline 5 & Afu [afu] & 'kapur sirih, kapur untuk makan sirih' \\
\hline 6. & Tambaku [tambakU] & 'tembakau kering, untuk bahan rokok' \\
\hline 7. & Nahi [nahI] & $\begin{array}{l}\text { 'sirih; dapat dikunyah bersama dengan pinang, kapur, dan } \\
\text { tembakau' }\end{array}$ \\
\hline 8. & $\begin{array}{l}\text { Rongko roo taa } \\
{[\text { rOykO rO?O ta?a] }}\end{array}$ & $\begin{array}{l}\text { 'rokok, gulungan tembakau, yang dibungkus dengan daun } \\
\text { lontar' }\end{array}$ \\
\hline 9. & Karodo [karO?dO] & 'makanan dari tepung dicampur kelapa dan gula' \\
\hline 10. & Bongi [bonI] & 'beras; padi yang terkelupas kulitnya' \\
\hline 11. & $\begin{array}{l}\text { Bongi monca }[\underline{b} \mathrm{OnI} \\
\text { mOnca }]\end{array}$ & 'beras berwarna kuning' \\
\hline
\end{tabular}




\begin{tabular}{|c|c|c|}
\hline 12. & Bongi kala [bonI kala] & 'beras berwarna merah' \\
\hline 13. & Bongi mee [bOpI mE?E] & 'beras berwarna hitam' \\
\hline 14. & Bongi bura [bOnI bura] & 'beras berwarna putih' \\
\hline 15. & Fare kapi [farE kapI] & 'padi ladang yang diikat/dijepit' \\
\hline 16. & $\begin{array}{l}\text { Fare monca }[\mathrm{farE} \\
\text { mOnca }]\end{array}$ & 'padi berwarna kuning' \\
\hline 17. & Fare kala [farE kala] & 'padi berwarna merah' \\
\hline 18. & Fare mee [farE mE?E] & 'padi berwarna hitam' \\
\hline 19. & Fare bura [farE bura] & 'padi berwarna putih' \\
\hline 20. & $\begin{array}{l}\text { Pangaha bunga [payaha } \\
\text { buya] }\end{array}$ & $\begin{array}{l}\text { 'jajan terbuat dari tepung dan beras ketan yang berbentuk } \\
\text { bunga' }\end{array}$ \\
\hline 21. & $\begin{array}{l}\text { Pangaha arunggina } \\
\text { [payaha aruygIna] }\end{array}$ & $\begin{array}{l}\text { 'panganan yang terbuat dari beras ketan, berbentuk bulat; } \\
\text { rengginang' }\end{array}$ \\
\hline 22. & $\begin{array}{l}\text { Jago karaba }[\mathrm{jagO} \\
\text { karaba] }\end{array}$ & 'jagung yang dimasak dengan cara diayak atau disangrai' \\
\hline 23. & Dolu [dOlu] & 'telur' \\
\hline 24. & Kapore [kapOrE] & $\begin{array}{l}\text { 'makanan dari tebung yang diberi bumbu kelapa dan gula } \\
\text { merah' }\end{array}$ \\
\hline 25. & Jago [jagO] & 'tanaman, buah jagung' \\
\hline 26. & Oi doa [OI dO?a] & $\begin{array}{l}\text { 'air; ciran yang tidak berwarna dan tidak berasa yang sudah } \\
\text { diberi doa' }\end{array}$ \\
\hline 27. & Roa dana [rOa dana] & 'tempayan yang terbuat dari tanah liat' \\
\hline 28. & $\begin{array}{l}\text { Malanta monca [malanta } \\
\text { mOnca] }\end{array}$ & 'kain kafan berwarna kuning' \\
\hline
\end{tabular}




\begin{tabular}{|c|c|c|}
\hline 29. & $\begin{array}{l}\text { Malanta bura [malanta } \\
\text { bura] }\end{array}$ & 'kain kafan berwarna putih' \\
\hline 30. & $\begin{array}{l}\text { Niu sambori }[\mathrm{nI} ? \mathrm{U} \\
\text { sambOrI }]\end{array}$ & 'setandan buah kelapa' \\
\hline 31. & $\begin{array}{l}\text { Ua sambori } \quad[\mathrm{u} ? \mathrm{a} \\
\text { sambOrI }]\end{array}$ & 'setandan buah pinang' \\
\hline 32. & $\begin{array}{l}\text { Nahi sapete [nahi } \\
\text { sapEtE] }\end{array}$ & 'seikat daun sirih' \\
\hline 33. & Dobu [dobu] & $\begin{array}{l}\text { 'tanaman tebu; air dalam batangnya manis, bahan membuat } \\
\text { gula' }\end{array}$ \\
\hline 34. & Karencu [karEncu] & 'ketupat yang dibuat memanjang' \\
\hline 35 . & Kahuntu [kahuntu] & 'ketupat yang dibuat berbentuk persegi' \\
\hline 36. & $\begin{array}{l}\text { Roo sancara }[\mathrm{rO} ? \mathrm{O} \\
\text { sancara }]\end{array}$ & 'daun tanaman sancara' \\
\hline 37. & Buja [buja] & 'tombak; senjata tajam yang ujungnya runcing' \\
\hline 38. & $\begin{array}{l}\text { Janga sanggapi [jaya } \\
\text { saygapI] }\end{array}$ & 'ayam yang dimasak dengan memanggang' \\
\hline 39. & Janga mori [jaya mOrI] & 'ayam yang masih hidup' \\
\hline 40. & Genda [gEnda] & $\begin{array}{l}\text { 'alat musik yang dipukul, terbuat dari kayu bulat memanjang } \\
\text { di dalamnya ada rongga' }\end{array}$ \\
\hline 41. & No $[\mathrm{nO}]$ & 'alat musik pukul, berbentuk bundar' \\
\hline 42. & Sarone [sarOnE] & 'suling; alat musik tiup' \\
\hline 43. & Paju [paju] & 'payung; alat pelindung dari hujan atau panas' \\
\hline 44. & Kalo [kalO] & 'buah pisang; buahnya berdaging dapat dimakan' \\
\hline 45. & Ilo lili [IIO IIII] & 'bahan yang udah mencair saat dipanaskan; lilin' \\
\hline
\end{tabular}




\begin{tabular}{|l|l|l|}
\hline 46. & Dupa [dupa] & 'dupa, kemenyan, saat dibakar asapnya berbau harum' \\
\hline 47. & Jima rima [jIma rIma] & $\begin{array}{l}\text { 'cincin besar, terbuat dari emas, perak, dan sebagainya yang } \\
\text { dipakai di tangan' }\end{array}$ \\
\hline 48. & Jima ancu [jIma ancu] & $\begin{array}{l}\text { 'cincin besar, terbuat dari emas, perak, dan sebagainya yang } \\
\text { dipakai di lengan atas' }\end{array}$ \\
\hline 49. & Kawari [kawarI] & 'aksesoris seperti kalung yang melingkar di leher' \\
\hline 50. & Baju bodo [baju bOdO] & 'baju khas suku bugis, dipakai juga oleh masyarakat Dompu' \\
\hline
\end{tabular}
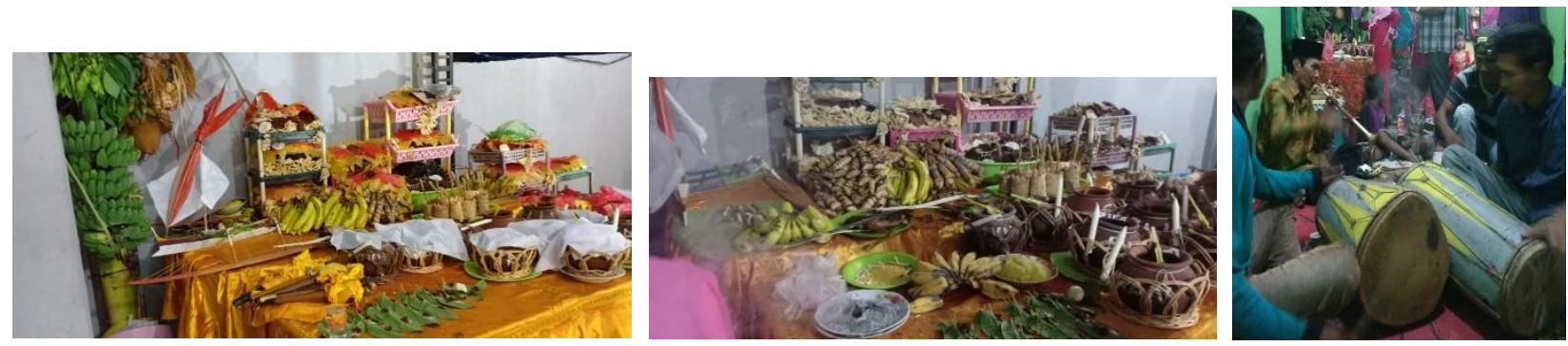

Gambar: soji ro sangga (sajen) wujud benda-benda hasil karya manusia. Dokumen pribadi.

Wujud kebudayaan sebagai benda-benda hasil karya manusia yang terdapat dalam prosesi suna ro ndoso masyarakat Dompu, ditemukan kurang lebih sekitar 50. Benda-benda tersebut merupakan wujud yang nyata berupa benda-benda hasil budaya dan hasil karya manusia. Bendabenda tersebut merupakan wujud benda yang berkaitan dengan hasil bumi dan wujud benda yang berkaitan dengan peralatan.

Sistem budaya yang tercermin dan tertuang dalam prosesi suna ro ndoso masyarakat Dompu merupakan perwujudan dari sistem sosial, sistem tingkah laku, dan kepribadian dari masyarakat setempat. Suna ro ndoso merupakan salah satu upacara adat atau prosesi adat yang harus dilaksanakan oleh masyarakat Dompu. Suna ro ndoso masyarakat Dompu merupakan hal yang sakral dan pelaksanaan upacara adat yang sakral karena berhubungan dengan kepercayaan. Suna ro ndoso merupakan sesuatu yang sangat penting untuk dilaksanakan karena berkaitan langsung dengan hubungan antara manusia dengan Tuhan, hubungan manusia dengan alam, dan hubungan manusia dengan sesama manusia. Suna ro ndoso mengajarkan kepada manusia bagaimana harus berbuat dan bersikap sesuai dengan perintah agama, saling melindungi, saling menjaga, saling mengayomi, serta berhubungan baik satu dengan yang lainnya.

Istilah-istilah dan aktivitas yang sudah disebutkan di atas merupakan hal yang wajib dilakukan dalam prosesi suna ro ndoso. Semua aktivitas tersebut memiliki fungsi sebagai penunjang yang mendukung ke arah pembentukan karakter dan kepribadian si anak yang disuna ro ndoso, juga 
sebagai upaya mendekatkan diri kepada Allah SWT. guna mengharapkan ridho dalam menjalani kehidupan bagi kedua orang tua dan keluarga serta kelak si anak menjadi dewasa.

\section{E. SIMPULAN}

Berdasarkan pembahasan mengenai wujud kebudayaan dalam prosesi suna ro ndoso masyarakat Dompu, ditemukan wujud-wujud kebudayaan berupa wujud kebudayaan sebagai suatu kompleks dari ide, gagasan, nilai, norma, peraturan dan sebagainya; wujud kebudayaan sebagai suatu kompleks aktivitas serta tindakan berpola dari manusia dalam masyarakat; dan wujud kebudayaan sebagai benda-benda hasil karya manusia.

Wujud dari ide, gagasan, nilai, norma, dan peraturan terlihat sebagai wujud ide/gagasan tentang ketuhanan, keselamatan, dan keberanian. Wujud aktivitas serta tindakan berpola ditemukan kurang lebih sekitar 13 kumpulan aktivitas serta tindakan berpola dari manusia dalam masyarakat pada prosesi suna ro ndoso. Wujud sebagai benda-benda hasil karya manusia yang terdapat dalam prosesi suna ro ndoso masyarakat Dompu, ditemukan kurang lebih sekitar 50. Ketiga wujud yang sudah disebutkan di atas, wujud benda dan wujud aktivitas merupakan wujud yang paling konkret untuk diamati sehingga sistem budaya dalam masyarakat Dompu dapat tercermin secara dominan dalam kedua wujud tersebut.

\section{F. Saran}

Prosesi suna ro ndoso masyarakat Dompu diharapkan dapat menjadi sarana pengetahuan dan pendidikan bagi masyarakat pada umumnya agar tetap melestarikan budaya yang sudah menjadi tradisi turun-temurun. Hasil penelitian ini diharapkan dapat bermanfaat bagi generasigenerasi muda agar menjaga dan melestarikan tradisi-tradisi yang masih hidup di tengah-tengah masyarakat, agar tidak dilupakan dan ditinggalkan seiring dengan terjadinya perkembangan zaman dan arus globalisasi. Oleh karena itu, penelitian ini diharapkan dapat menjadi bahan diskusi bagi penelitian lain dalam melakukan penelitian lanjutan.

\section{DAFTAR PUSTAKA}

Abdullah, Wakit. 2013. Kearifan Lokal dalam Bahasa dan Budaya Jawa Masyarakat Nelayan di Pesisir Selatan Kebumen (Sebuah Kajian Etnolinguistik). Disertasi. Surakarta: Universitas Sebelas Maret.

Baehaqie, Imam."Jenang Mancawarna Sebagai Simbol Multikulturalisme Masyarakat Jawa”. dalam Jurnal Komunitas 6 (1) (2014): 180-188.

Hamzah, Muslimin. 2004. Ensiklopedia Bima. Yogyakarta: Transglobal.

Ismail, M. Hilir. dan Malingi, Alan. 2012. Upacara Daur Hidup Masyarakat Bima-Dompu. Yogyakarta: Transglobal. 
Koentjaraningrat. 2009. Pengantar Ilmu Antropologi Edisi Revisi 2009. Jakarta: PT Rineka Cipta.

Mahsun. 2017. Metode Penelitian Bahasa: Tahapan Strategi, Merode, dan Tekniknya. Depok: PT Rajagrafindo Persada.

Moleong, Lexy J. 2015. Metode Penelitian Kualitatif. Bandung: Remaja Rosdakarya.

Pujileksono, Sugeng. 2016. Pengantar Antropologi: Memahami Realitas Sosial Budaya. Malang: Intrans Publishing.

Saleh, I.M. 1985. Sekitar Kerajaan Dompu. Dompu: Nggusu Waru.

Setiadi, Elly M dkk. 2013. Ilmu Sosial dan Budaya Dasar Edisi Ketiga. Jakarta: Kencana Prenadamedia Group.

Siswantoro. 2015. Metode Penelitian Sastra; Analisis Psikologis. Surakarta:

Muhammadiyah University Press.

Suarsini, Ni Nengah. 2017. Tradisi Ngelawang Pada Hari Raya Kuningan Di Desa Pakraman Asak Pagutan: Sebuah Kajian Etnolingyistik. Mataram: Unram. 